\title{
Simuladores como Estratégia de Ensino de Diagnóstico por Imagem para o Curso de Medicina Veterinária da FZEA-USP
}

\author{
Maria Cristina Ferrarini Nunes Soares Hage* \\ Medicina Veterinária da Faculdade de Zootecnia e Engenharia de Alimentos da Universidade de São Paulo \\ * Autor para correspondência: crishagedpi@gmail.com
}

\section{RESUMO}

O presente relato apresenta duas experiências com simuladores artesanais utilizados como método de ensino de diagnóstico por imagem para alunos do curso de graduação em Medicina Veterinária da FZEA-USPPirassununga. Os modelos artesanais foram produzidos com materiais de baixo custo e fácil acesso, e promoveram o incremento no aprendizado de habilidades cognitivas, técnicas, emocionais e psicomotoras. As experiências geraram duas publicações internacionais referenciadas neste relato.

Palavras-chave: Corpos Estranhos; Efusão Pericárdica; Modelos; Pericardiocentese; Treinamento; Ultrassonografia.

\begin{abstract}
The present report presents two experiments with handmade simulators used as a method of teaching Diagnostic Imaging for students of the undergraduate course in Veterinary Medicine of the FZEA-USP-Pirassununga. The handmade models were produced with materials of low cost, easy access and promoted the increment in the learning of cognitive, technical, emotional and psychomotor skills. The experiences generated two international publications referenced in this report.
\end{abstract}

Keywords: Foreign Bodies; Pericardial Effusion; Phantom; Pericardiocentesis; Training; Ultrasonography.

Em um dia na rotina da Unidade Didático Clínico Hospitalar (UDCH-FZEA-USP), deparei-me com um caso de efusão pericárdica. Este consiste em excesso de líquido no interior do pericárdio que recobre o coração, apresenta várias causas e coloca em risco a vida do animal por tamponamento cardíaco: quando a pressão intrapericárdica se torna elevada e comprime o coração levando a baixo débito cardíaco e insuficiência cardíaca congestiva (MILLER et al., 2004). Como ação de urgência, realizei uma pericardiocentese guiada pelo ultrassom.

A pericardiocentese é um procedimento relativamente simples, mas que exige experiência, já que é realizada em atendimentos de urgência em momentos inesperados. Diante desse fato, comecei a me perguntar como ensinar os princípios de tal processo aos alunos da graduação, pois não se trata de uma intervenção que aparece para ser feita todos os dias, e, mesmo se aparecesse, não seria possível deixar um aluno inexperiente realizá-la e muito menos dispor de casos suficientes para que todos os alunos pudessem desfrutar da experiência, que poderia até ser traumática se fossem expostos a ela sem a devida prática.

Sendo assim, imaginei a possibilidade de desenvolvimento de um simulador de pericardiocentese guiada pelo ultrassom a custo baixo. Essa experiência traria a todos os alunos a possibilidade de discutir o assunto previamente, mostrar o caso atendido, manusear os aparatos necessários, como cateteres, seringa, torneira de três vias, e realizar o procedimento de forma mimetizada nos mínimos detalhes e com segurança, fortalecendo nos alunos a autoestima.

Já existem no mercado simuladores comerciais para pericardiocentese, mas os preços são altos e, na crise atual, optar por algo mais barato pareceu ser coerente e de bom senso. Porém, precisava ser testado para verificar junto aos alunos a aceitação. 
Propus, então, como projeto do Programa de Pré-Iniciação Científica (Pré-IC) 2014-2015 USP/ Santander, o título "Valor de Simuladores Artesanais no Treinamento de Alunos da Medicina Veterinária para Realização de Procedimentos Invasivos Guiados pelo Ultrassom", este o primeiro projeto que desenvolvi na USP, com a ajuda da aluna do Ensino Médio Ana Beatriz Massaferro, da Escola Técnica Tenente Aviador Gustavo Klug (Pirassununga, SP), envolvendo ainda alunas da graduação e pós-graduação.

O resultado dessa experiência, um simulador feito com gelatina, balões de borracha, coração de frango, tinta guache e faixa de borracha, pode ser conferido no resumo apresentado no $1^{\circ}$ Congresso da Graduação da USP (HAGE et al., 2015) e em publicação internacional no periódico Advances in Physiology Education (HAGE et al., 2016). No texto, ensinamos como produzir o modelo, como foi a aplicação aos alunos - que responderam ao questionário com questões abertas e fechadas do tipo EVA (escala visual analógica) - e apresentamos os resultados alcançados.

A aceitação foi tamanha que testamos em alunos da graduação do curso de Medicina Veterinária que já haviam cursado a disciplina ZMV1336 Diagnóstico por Imagem e também em profissionais médicos-veterinários (graduados, residentes, pós-graduandos e pós-doutorandos).

A experiência foi gratificante e já foi utilizada em outra turma da graduação. Nesta, solicitei que eles preparassem os modelos em casa em duplas, e para minha grata surpresa todos trouxeram, e isto tornou a atividade ainda mais lúdica e pró-ativa.

A compreensão e a aceitação por parte dos alunos com relação aos simuladores artesanais, no que tange a incremento no aprendizado de habilidades cognitivas, técnicas, emocionais e psicomotoras, trouxeram motivação para novas experiências de ensino com metodologias ativas.

O segundo projeto desenvolvido na mesma linha de ensino de ultrassonografia com simuladores foi proposto para uma Iniciação Científica RUSP (2014/2015), que contou com a então aluna de graduação Carolina Mariano Beraldo e uma aluna da pós-graduação. Ele foi intitulado "O Valor de Simuladores Artesanais no Treinamento de Alunos do Curso de Medicina Veterinária para Detecção Ultrassonográfica de Corpos Estranhos Radiotransparentes".

Corpos estranhos são estruturas engolidas pelos animais ou que perfuram a sua pele e músculos. Portanto, os modelos foram desenvolvidos com bico de chupeta, bolinha de borracha, meia ou fio de nylon inseridos em "tripa" de suíno, caroço de manga, bem como farpas de madeira inseridas em peça de carne de açougue. Nesse projeto, a intenção foi mostrar que objetos radiotransparentes, ou seja, aqueles que não aparecem nas radiografias convencionais, podem ser identificados por meio da ultrassonografia, porém o reconhecimento requer treinamento. Novamente com a intenção de promover esse treinamento, foram expostos alunos voluntários do curso, e a aceitação foi ampla. $\mathrm{O}$ artigo resultante desse trabalho foi publicado pelo periódico internacional Advances in Physiology Education (BERALDO et al., 2017) e o resumo apresentado no $2^{\circ}$ Congresso de Graduação da USP (BERALDO et al., 2016).

Novos projetos foram elaborados e estão em desenvolvimento. Com a utilização de simuladores é possível atender aos anseios dos alunos. Os estudantes foram fonte de inspiração, e a aceitação combustível para a continuidade dessas invenções. $\mathrm{O}$ fato de serem simuladores artesanais nos traz a certeza de continuidade do ensino mesmo em tempos difíceis. Assim, metodologias ativas de ensino-aprendizagem fornecem a base da interação aluno-professor na disciplina de Diagnóstico por Imagem com ganho na formação do profissional Médico Veterinário oriundo da FZEA-USP.

\section{Bibliografia}

BERALDO, C. M.; LOPES, E. R. \& HAGE, M. C. F. N. S. "O valor de Simuladores Artesanais no Treinamento de Alunos do Curso de Medicina Veterinária para Detecção Ultrassonográfica de Corpos Estranhos Radiotransparentes". Anais do $2^{\circ}$. Congresso de Graduacão da USP, p. 193. Disponível em: www.prg.usp.br/wp-content/ uploads/anais_congresso_graduacao_usp_2016.pdf.

; HAGE, R. \& HAGE, M. C.

F. N. S. "The Value of Homemade Phantoms for 
Training Veterinary Students in the Ultrassonographic Detection of Radiolucent Foreign Bodies". Advances in Physiology Education, vol. 41, 2017, pp. 94-98.

HAGE, M. G. F. N. S.; MASSAFERRO, A. B.; LOPES, E. R.; BERALDO, G. M. \& DANIEL, J. "Value of Artesanal Simulators to Train Veterinary Students in Performing Invasive Ultrasound-Guided Procedures". Advances in Physiology Education, vol. 40, pp. 98-103, 2016.

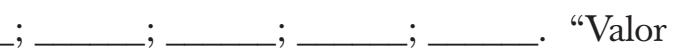

de Simuladores Artesanais no Treinamento de Alunos da Medicina Veterinária para Realização de Procedimentos Invasivos Guiados pelo Ultrassom". Anais do $1^{\circ}$ Congresso de Graduação da USP, pp. 63-64. 2015. Disponível em: www.prg.usp.br/wp-content/uploads/ anais2015_corrigido.pdf.

MILLER, M. W. \& SISSON, D. D. "Distúrbios Pericárdicos". In: ETTHINGER, S. J. \& FELDMAN, E. C. Tratado de Medicina Interna Veterinária. 5th ed. Rio de Janeiro: Editora Guanabara Koogan, 2004, pp. 978-992.

Publicado em 31/03/2017. 